\title{
Synthesis, Characterization, and Applications of Dendrimer-Encapsulated Zero-Valent Ni Nanoparticles as Antimicrobial Agents
}

\author{
A. Mazumder, ${ }^{1}$ J. Davis, ${ }^{2}$ V. Rangari, ${ }^{3}$ and M. Curry ${ }^{1,3}$ \\ ${ }^{1}$ Chemistry Department, Tuskegee University, Tuskegee, AL 36088, USA \\ ${ }^{2}$ Biology Department, Tuskegee University, Tuskegee, AL 36088, USA \\ ${ }^{3}$ Center for Advance Materials, Tuskegee University, Tuskegee, AL 36088, USA \\ Correspondence should be addressed to M. Curry; currym@mytu.tuskegee.edu
}

Received 1 July 2013; Accepted 27 August 2013

Academic Editors: Y. Barnakov, J. Gu, Z.-M. Liao, and S. Sun

Copyright ( 2013 A. Mazumder et al. This is an open access article distributed under the Creative Commons Attribution License, which permits unrestricted use, distribution, and reproduction in any medium, provided the original work is properly cited.

\begin{abstract}
Dendrimers have emerged as one of the most promising, cost-effective synthesizing methodologies in which highly monodispersed metallic nanoparticles can be produced with varied chemical functionalities. In this report, we have investigated the synthesis and application of as-synthesized dendrimer-encapsulated zero-valent nickel " $\mathrm{Ni}(0)$ " nanoparticles (NPs), using a fourth generation (G4) $\mathrm{NH}_{2}$-terminated poly(amido)amine (PAMAM) dendrimer as the host template, as potential antimicrobial agents. Apparently, based on ultraviolet visible spectroscopy (UV-vis) and transmission electron microscopy (TEM) analyses, Ni(0) NPs with an average measured size less than $10 \mathrm{~nm}$ in diameter were formed within the interior void cavity of the dendrimer structure. X-ray diffraction (XRD) analysis indicates that the NPs exhibited a single-phased, face-centered-cubic (fcc) crystallographic structure. Furthermore, to evaluate the antimicrobial activity of the dendrimer-encapsulated $\mathrm{Ni}(0) \mathrm{NPs}$, disk diffusion assay and minimum inhibitory concentration (MIC) examinations, both antimicrobial tests, were conducted. Subsequently, UV-vis analyses, after exposure of the dendrimer-encapsulated $\mathrm{Ni}(0) \mathrm{NPs}$ to both Gram-negative and Gram-positive bacteria, revealed that the dendrimer-encapsulated particles prevented the growth of bacteria during the culturing stage.
\end{abstract}

\section{Introduction}

Interest in nanoparticles synthesis has intensified within the scientific community due to their large amount of surfacearea-to-volume ratio, which can be modified for use in a wide range of technological and chemical systems. As of date, nanosized inorganic particles with simple or complex structures are currently being used in electronics [1], optical devices $[2,3]$, sensor devices $[4,5]$, surface enhanced Raman scattering (SERS) $[6,7]$, catalysis [8-10], biomedicine [11], wound healing [12], antimicrobial properties $[13,14]$, gene expression [15], and magnetic resonance imaging [16]. However, due to the limitation of current synthesizing methodologies to produce nanoparticles with precise physical and chemical details, concerns have increased over nanoparticle usage in the healthcare industry. Furthermore, with increasing microbial organisms' resistant to various antibiotics and uncertainties in healthcare costs, the emergence of more cost effective new methodologies to produce nanosized particles with specific physical and chemical functionalities and with limited or no resistance has piqued the interest of scientists around the globe [11-15]. That is, the development of more cost efficient synthetic methodologies with the capability of producing nanoparticles with highly controllable sizes and chemical functionalities will increase the possibilities of developing new types of nanostructures with well-designed (or even specific) functional surfaces or architectures that can be used in the biomedical industry as antimicrobial agents.

The antimicrobial activity exhibited by nanoparticles has been attributed to their relatively smaller sizes and high amount of surface-area-to-volume ratio that allows nanoparticles to interact closely with membranes of viruses, fungi, or bacteria rather than the normal mechanism of releasing metal ions in solution [17]. It is well known that 
due to the high surface-area-to-volume ratio, microscopic amounts of metal nanoparticles can provide antimicrobial effects to hundreds of square meters of its host material. Many studies have shown that $\mathrm{Ag}, \mathrm{Cu}, \mathrm{Ni}$, and $\mathrm{Co}$ (and their oxides) exhibit good antimicrobial activity against various bacteria [18-21]. However, as of date, only a few studies have reported the antibacterial properties of nickel nanoparticles due to stability issues. One of the main concerns in the synthesis of $\mathrm{Ni}$ nanoparticles is the rapid oxidation when exposed to ambient conditions and its high self-affinity to aggregate upon formation. However, based on many recent literature reports, dendrimers would make an ideal method of synthesizing Ni nanoparticles in which the size, shape, and chemical reactivity could be controlled.

Dendrimers are macromolecules with highly branched three-dimensional architecture and have some unique properties because of their globular shape and the presence of free-void volume in their internal cavities. Due to the free-void volume located within the interior structure of the dendrimer, it can encapsulate guest molecules in its macromolecular interior, thus coating the nanoparticles and potentially preventing them from further oxidation and aggregation $[22,23]$. Moreover, it has been reported that the size of Ni nanoparticles formed through dendrimer templating depends on the metal-to-dendrimer ratio and generation of the dendrimer [24]. Through the details of the dendrimer architecture, nanoparticles with high surface-area-to-volume ratios can be produced and should exhibit a high chemical reactivity as a biological agent. Thus, in this study, we evaluated the antimicrobial properties of dendrimer-encapsulated Ni nanoparticles against Gram-positive and Gram-negative bacteria.

\section{Experimental}

2.1. Materials. Starburst amine terminated PAMAM dendrimers of generation four (G4-PAMAM) was used in this experiment. Dendrimer solutions were prepared as $10 \mathrm{wt} \%$ in methanol. $\mathrm{Ni}\left(\mathrm{NO}_{3}\right)_{2} \cdot 6 \mathrm{H}_{2} \mathrm{O}$ was used as the metal source. Methanol, THF, and deionized water were used as solvents and sodium borohydride $\left(\mathrm{NaBH}_{4}\right)$ were used as the reducing agent. All chemicals were of analytical reagent grade and purchased from Sigma Aldrich Chemical Co. and used asreceived.

2.2. Preparation of Solutions. $10 \mathrm{~mL}$ of $200 \mu \mathrm{M}$ G4-PAMAM dendrimer stock solution was prepared in methanol. From the stock solution, dilute solutions $(2 \mu \mathrm{M})$ were prepared and mixed with a $55 \mathrm{~mol}$ or $147 \mathrm{~mol}$ equivalent of $\mathrm{Ni}\left(\mathrm{NO}_{3}\right)_{2} \cdot 6 \mathrm{H}_{2} \mathrm{O}$ solution that was prepared in THF. The calculated concentrations of the 55 mole and 147 mole equivalents of $\mathrm{Ni}\left(\mathrm{NO}_{3}\right)_{2} \cdot 6 \mathrm{H}_{2} \mathrm{O}$ to dendrimer were $110 \mu \mathrm{M}$ and $294 \mu \mathrm{M}$, respectively. A $1.0 \mathrm{M} \mathrm{NaBH}_{4}$ solution was prepared in deionized water and used as the reducing agent.

2.3. Synthesis of Ni-Dendrimer. An appropriate stoichiometric ratio of $\mathrm{Ni}\left(\mathrm{NO}_{3}\right)_{2} \cdot 6 \mathrm{H}_{2} \mathrm{O}$ was added to $2 \mu \mathrm{M}$ G4-PAMAM dendrimer solution with continuous stirring. Subsequently,

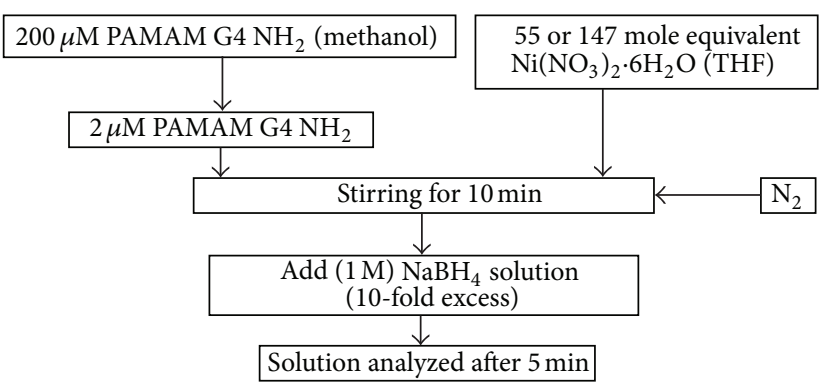

FIGURE 1: Flow chart revealing the synthesizing methodology for the formation of dendrimer-encapsulated $\mathrm{Ni}(0)$ nanoparticles.

this solution contains dendrimer-metal ion complexes (G4Den- $\left(\mathrm{Ni}^{2+}\right)_{x}$, where $x=55$ - or 147 -mole ratio). After 10 minutes of stirring, a 10 -fold excess of $1.0 \mathrm{M} \mathrm{NaBH}_{4}$ was added to the complexed solution to reduce the bivalent nickel to zero-valent nickel $\left(\mathrm{Ni}^{2+} \rightarrow \mathrm{Ni}^{0}\right)$. (Note that the entire stepwise reaction procedure is described in Figure 1.) Upon reduction, a solution color change was observed, colorless to golden brown in color, indicating the formation of nickel metal. To prevent metal oxidation during the reduction process, the experiments were conducted under a $\mathrm{N}_{2}$ gas atmosphere. It is important to note that after reduction of the Ni nanoparticles, exposure for periods longer than 48-96 hours to ambient conditions resulted in $\mathrm{Ni}$ oxide formation.

2.4. Characterization Techniques. We applied a range of techniques to evaluate the chemical and physical properties of the as-synthesized zero-valent nickel nanoparticles. The physical and chemical properties of the nickel nanoparticles were determined by analyzing them using a series of characterization techniques such as ultraviolet visible spectroscopy (UV-vis), transmission electron microscopy (TEM), and Xray diffraction (XRD).

2.4.1. UV-Visible Spectroscopy. Absorbance spectra were collected for the dendrimers and $\mathrm{Ni}$ salt solutions and for the complexed $\left(\mathrm{G} 4-\mathrm{Den}-\left(\mathrm{Ni}^{2+}\right)_{x}\right.$ solutions, before chemical reduction. All absorbance measurements were carried out in a $1.0 \mathrm{~cm}$ optical path length quartz crystal cuvette and spectra analyses were obtained using a Hewlett-Packard HP 8453 UV-Visible Spectrophotometer. The wavelength range of analysis was $250-800 \mathrm{~nm}$.

2.4.2. X-Ray Diffraction Spectroscopy. X-ray diffraction was used to determine the crystallographic structure of the dendrimer-encapsulated $\mathrm{Ni}(0)$ nanoparticles. X-ray diffraction analyses were carried out using a Rigaku D/MAX $2200 \mathrm{X}$-ray diffractometer with a diffracted beam graphite monochromatic running on $\mathrm{Cu} \mathrm{K} \alpha$ radiation. The experiment was performed from $0^{\circ}$ to $80^{\circ}$ of $2 \theta$ angle at a rate of 2 degrees per minute. The data was collected and peaks were analyzed using PDF data base of Joint Committee on Powder Diffraction Standards (JCPDS). The mass of Ni metal in each sample was calculated based on the mass of the dendrimer sample analyzed. 


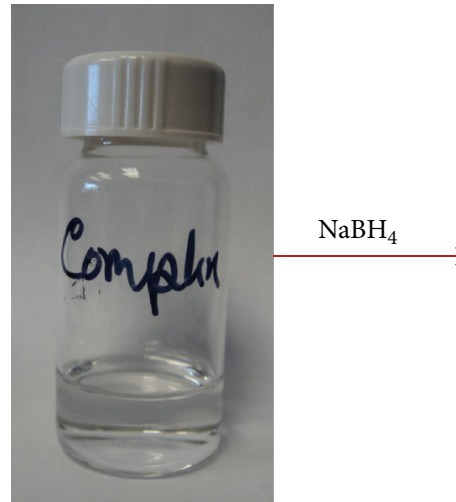

(a) G4-Den- $\left(\mathrm{Ni}^{2+}\right)_{x}$

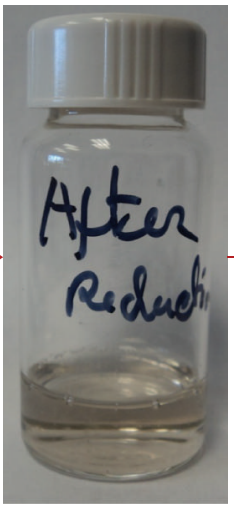

(b) G4-Den-(Ni)

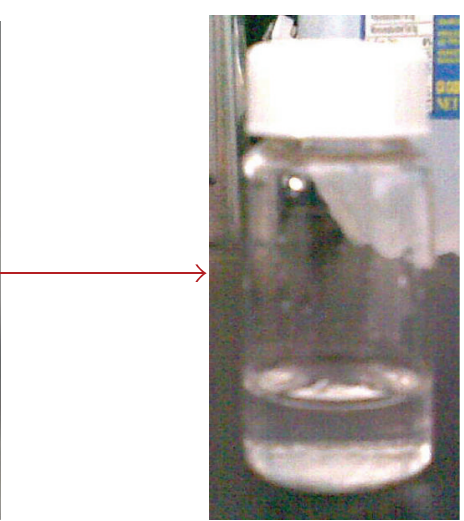

(c) After exposing in atmospheric conditions

Figure 2: Pictures of the dendrimer solutions before and after complexation revealing the formation of Ni nanoparticles during every step of the chemical reaction: (a) Ni-Den complex, (b) after reduction, and (c) exposed in air.

2.4.3. TEM Imaging of Nanoparticles. TEM images were obtained using a high-resolution transmission electron microscopy (HRTEM) (JOEL JEM 2010 Ltd., Tokyo, Japan). One drop of the complex was deposited on the copper grid (carbon-coated copper grid, 200 mesh) and allowed to dry for 10 minutes. Using a high-energy electron beam, the sample microstructure was examined. For each sample, different parts of the grid were used to determine both average shape and size distributions.

\subsection{Antimicrobial Test}

2.5.1. Sample Preparation for Antimicrobial Test. After reduction, the resultant solution was dried in an oven at $65^{\circ} \mathrm{C}$ for 24 hours and by passing $\mathrm{N}_{2}$ gas. Then $2 \mathrm{~mL}$ deionized water was added, and vortexing was done in order to promote particles that were well dispersed in water. $\mathrm{Ni}\left(\mathrm{NO}_{3}\right)_{2} \cdot 6 \mathrm{H}_{2} \mathrm{O}$ salt solution was prepared in THF, and sample was as prepared as nanoparticles solution. To test the antimicrobial properties of formed Ni nanoparticles, two different concentrations of $\left(\mathrm{NO}_{3}\right)_{2} \cdot 6 \mathrm{H}_{2} \mathrm{O}$ were used, $110 \mu \mathrm{M}$ and $294 \mu \mathrm{M}$.

2.5.2. Evaluation of Antimicrobial Properties. For antibacterial experimentation, Escherichia coli (Gram-negative bacteria) and Bacillus subtilis (Gram-positive bacteria) were selected as indicators. All disks and materials were sterilized in an autoclave before experiments. The antibacterial activities of G4-Den- $\left(\mathrm{Ni}^{2+}\right)$ solution were measured by two methods: paper disk diffusion assay and minimal inhibitory concentration (MIC).

2.5.3. Paper Disk Diffusion Assay. The disk diffusion assay was performed by culturing bacteria inoculated on a petri plate containing an agar medium. Then $5 \mathrm{~mm}$ filter paper disk was placed onto agar plate seeded with various microorganisms. The disk was saturated with different amounts of nanoparticles solutions. After $24 \mathrm{~h}$ of incubation at $37^{\circ} \mathrm{C}$ in an oven, the diameters of the microbial growth around the disk were observed. This area is called inhibition zones.

2.5.4. Minimum Inhibitory Concentration Assay. The minimum inhibitory concentration assay is a method used to determine the lowest concentration and amount of a particular antibiotic needed to destroy bacteria. This assay is naturally performed on planktonic (free floating) bacterial cells. Serial dilutions of the antibiotic (representing different amount of the antibiotic) are added to a growth medium in separate test tubes. These tubes are then immunized with the bacteria. Each of these tubes has growth media inoculated with a standard concentration of bacteria and the respective antibiotic concentration. Then the tubes are allowed to incubate overnight. Both tubes that appear turbid are indicative of bacterial growth while tubes that remain clear indicate no growth. The MIC of the antibiotic is the lowest concentration that does not show bacterial growth [25]. MIC values for dendrimer-encapsulated $\mathrm{Ni}(0)$ nanoparticles where the absence of growth could be observed were recorded. At the end of the incubation period, the test tubes were evaluated for the presence or absence of growth. By thermo spectronic UV-visible spectrophotometer optical density (turbidity) of the samples was measured at $600 \mathrm{~nm}$ wavelength. MIC value is not constant. It varies with the change in test organism, incubation time, and the condition of the culture medium.

\section{Results and Discussion}

$110 \mu \mathrm{M}$ and $294 \mu \mathrm{M} \mathrm{Ni}\left(\mathrm{NO}_{3}\right)_{2} \cdot 6 \mathrm{H}_{2} \mathrm{O}$ salt solution were added to $2 \mu \mathrm{M}$ G4-PAMAM dendrimer solution while stirring continuously. $\mathrm{NaBH}_{4}$ was then added to the complexed solution. After introduction of the reducing agent $\left(\mathrm{NaBH}_{4}\right)$, a color shift from clear to golden brown can be observed in the G4-Den- $\left(\mathrm{Ni}^{2+}\right)_{x}$ complexed solution (see Figure 2(a)). Note that when reduced solutions were exposed to ambient conditions for more than 24-48 hours, the color changed from 


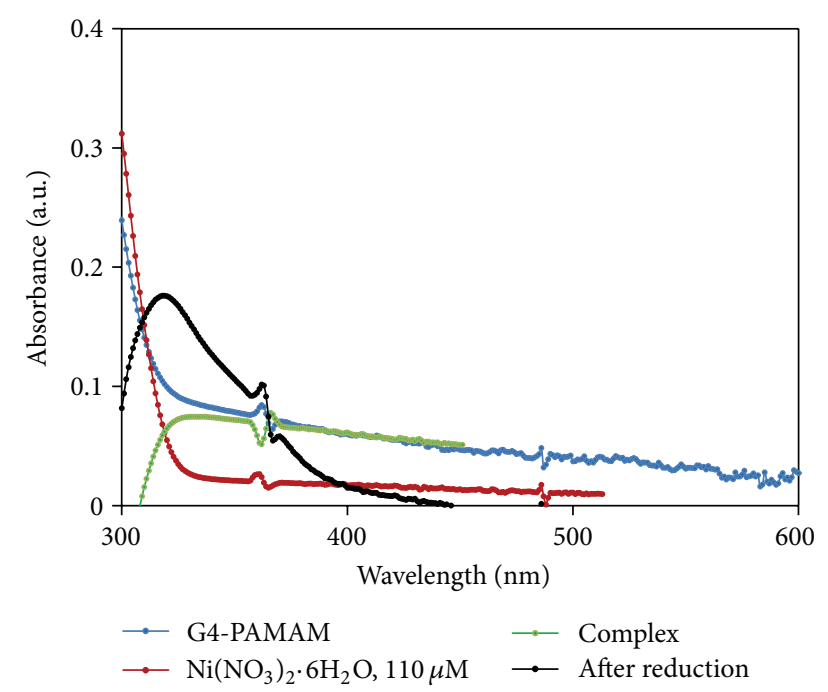

FIgURE 3: UV-vis spectra of G4-Den- $\left(\mathrm{Ni}^{2+}\right)$ before and after reduction. (Note that the negative-going absorptions are due to imperfect subtraction of the solvent background at $\lambda<300 \mathrm{~nm}$ ).

a golden-brownish color to a white powdery like substance (see Figure 2(c)). Knecht and coworkers showed similar results during the synthesis of Ni nanoparticles using amineterminated, sixth-generation PAMAM dendrimers substituted on the periphery with dodecyl functional groups [24].

3.1. UV-Vis Absorption Spectroscopy Analysis. Figure 3 shows a typical collection of UV-vis spectra for dendrimer-mediated $\mathrm{Ni}(0)$ formation during the synthesis process. Clearly, both the G4-PAMAM dendrimers and the $\mathrm{Ni}\left(\mathrm{NO}_{3}\right)_{2} \cdot 6 \mathrm{H}_{2} \mathrm{O}$ salt exhibit an absorbance band below the wavelength of $300 \mathrm{~nm}$. Similar results were observed by Knecht and coworker when the absorbance of a G6-dendrimer and Ni salts was measured before complexation [24]. After mixing of $\mathrm{Ni}\left(\mathrm{NO}_{3}\right)_{2} \cdot 6 \mathrm{H}_{2} \mathrm{O}$ and dendrimer solutions and 10 minutes of stirring, UVvis spectra of the Den- $\mathrm{Ni}^{2+}$ complexes were collected. Apparently, upon complexation, a shift in the absorbance wavelength of the UV-vis spectra can be observed for the complexed mixture $(\lambda>300 \mathrm{~nm})$ and is indicative of interactions occurring between dendrimers and $\mathrm{Ni}^{+2}$ ions. This can be explained through an ion-pair exchange between the dendrimer and the $\mathrm{Ni}^{+2}$. Numerous literature reports, after extensive investigations, have indicated that the interaction between dendrimers and $\mathrm{Ni}^{+2}$ occurs as a result of a ligand-to-metal charge-transfer mechanism with the amido groups housed in the interior of the dendrimer structure [24-27]. Furthermore, after addition of the reducing agent, $\mathrm{NaBH}_{4}$, an absorbance around $330 \mathrm{~nm}$ is observed indicating that the G4-Den- $\left(\mathrm{Ni}^{2+}\right)_{x}$ complexation has been reduced to dendrimer-encapsulated $\mathrm{Ni}(0)$ nanoparticles (Den-Ni(0)). Similar results were reported by Knecht et al. in which dendrimer-complexed Ni NPs exhibited an absorbance band around $330 \mathrm{~nm}$ after the addition of a reducing agent and analyzed by UV-vis spectroscopy [24].
3.2. XRD and TEM Analysis of Intradendrimer Ni(0) Particles. $\mathrm{XRD}$ and TEM analyses were performed to provide insight into the crystal structure, size, and shape of the dendrimersynthesized $\mathrm{Ni}(0)$ nanoparticles. Figures $4(\mathrm{a})$ and $4(\mathrm{~b})$ show typical XRD patterns for $\mathrm{Ni}(0)$ nanoparticles and the G4PAMAM dendrimers, respectively. Figure 4(a) reveals XRD peak values at $42^{\circ}$ and $49^{\circ}$, which are associated with the (111) and (200) planes of orientation, respectively. These values correspond well to the typical diffraction patterns observed for face-centered cubic (fcc) Ni nanoparticles [27, 28]. Similar results have been reported by Harish and coworker during the formation of nickel hydroxide nanoparticles [29]. In addition, two other peaks can be observed at $2 \theta$ values of $25^{\circ}$ and $29^{\circ}$. One may speculate that the observance of these peak values $\left(25^{\circ}\right.$ and $\left.29^{\circ}\right)$ is indicative of the existence of multiple crystal phases. However, in this case, it is justifiable to assume that these peak values correspond to the crystal structure of the reducing agent, $\mathrm{NaBH}_{4}$, with orientations of (111) and (022) [30].

Figure 5 provides representative high resolution plan view TEM micrographs for the dendrimer-encapsulated $\mathrm{Ni}(0)$ nanoparticles. Analysis of the TEM micrograph in Figure 5 clearly reveals that the as-prepared Ni nanoparticles are roughly spherical in shape and exhibit an average diameter around $10 \mathrm{~nm}$. The diameter of the $\mathrm{Ni}(0)$ nanoparticles are further confirmed by using the Debye-Scherrer equation, which revealed based on the FWHM of the (111) XRD reflection plane an estimated average particle size of $9.7 \mathrm{~nm}$ as calculated, which is in good agreement with the observed average size as revealed by TEM imaging. Hence, based on XRD and TEM analyses and the absence of any additional peaks outside of the reducing agent, the as-synthesized dendrimer-encapsulated $\mathrm{Ni}(0)$ nanoparticles are spherical in shape, single-phased, fcc phase only, and with an average particle size around $10 \mathrm{~nm}$.

\subsection{Antimicrobial Activity of Dendrimer-Encapsulated Ni(0)} Nanoparticles. Antibacterial activities of as-synthesized dendrimer-encapsulated nanoparticles against Gram-negative and Gram-positive bacteria considered in the present study were qualitatively and quantitatively assessed by determining/observing the presence of inhibition zones and MIC values. Figure 6 shows antimicrobial activity of dendrimer synthesized Ni nanoparticles against $E$. coli bacteria. As can be observed from the zones of inhibition, $\mathrm{Ni}(0)$ nanoparticles formed via dendrimer templating exhibited antimicrobial activity. Furthermore, it can be observed that increasing the concentration of the dendrimer-encapsulated $\mathrm{Ni}(0)$ nanoparticles in the presence of the E. coli bacteria leads to an increase in the amount of antimicrobial activity observed. When the concentrations of the nanoparticles are increased to $200 \mu \mathrm{L}$, Figure 6(b), wider zones of inhibition are observed. That is, the antimicrobial activity improved with increasing amount of dendrimer-encapsulated $\mathrm{Ni}(0)$ nanoparticles and thus they are good inhibitors of E. coli growth [13].

It has been reported that pure G4-PAMAM dendrimers exhibit some antimicrobial activity against $E$. coli at higher 


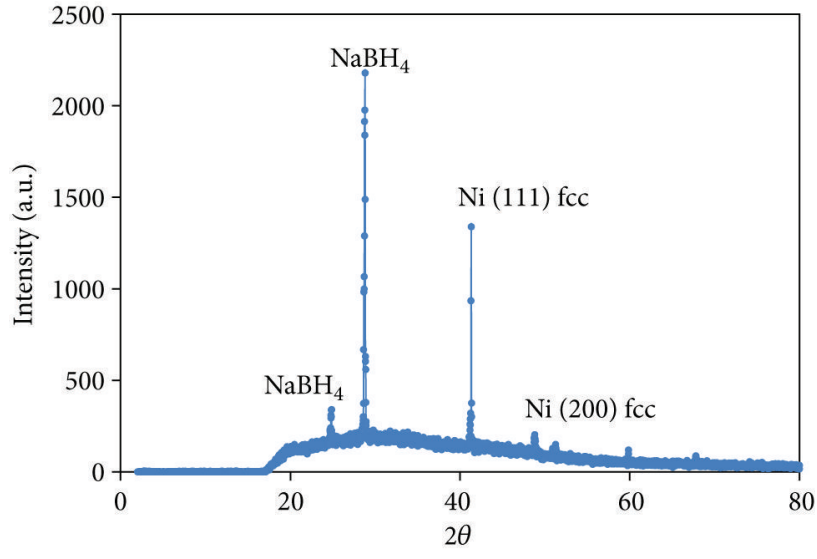

(a)

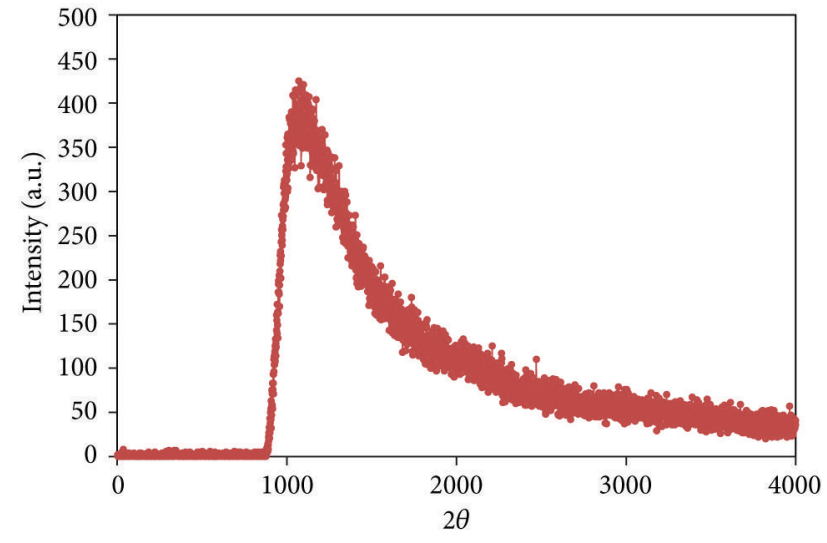

(b)

FIGURE 4: X-ray diffraction pattern for (a) dendrimer-encapsulated Ni after reduction and (b) PAMAM dendrimer $\left(\mathrm{G} 4 \mathrm{NH}_{2}\right)$.

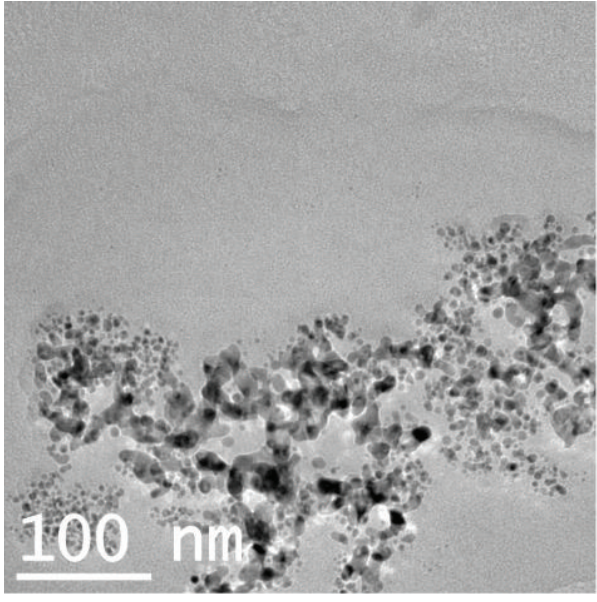

(a)

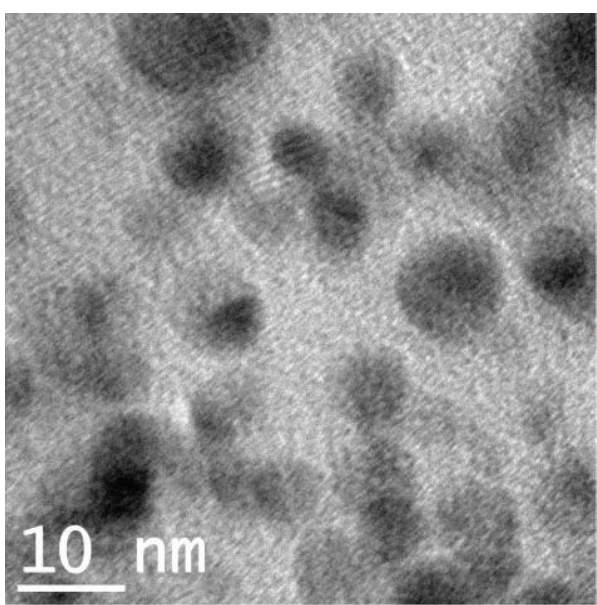

(c)

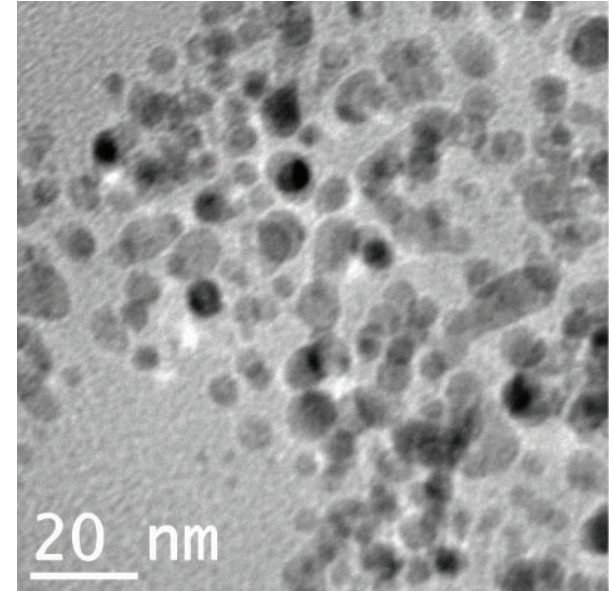

(b)

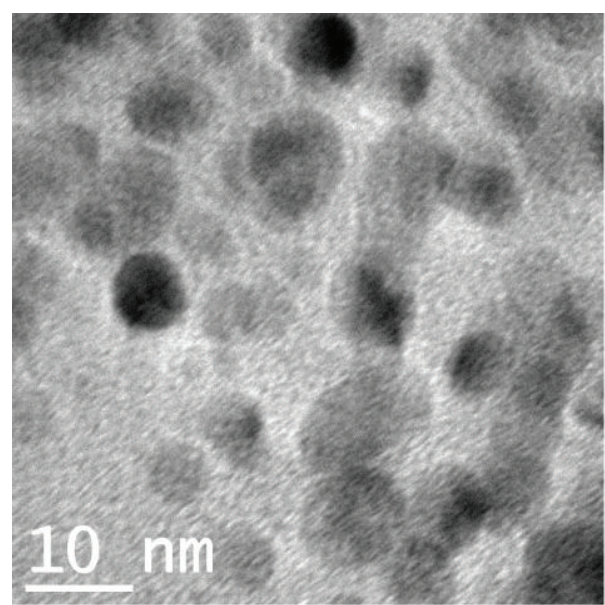

(d)

FIgURE 5: Plan view TEM image revealing the size and shape of dendrimer-encapsulated $\mathrm{Ni}(0)$ nanoparticles. 


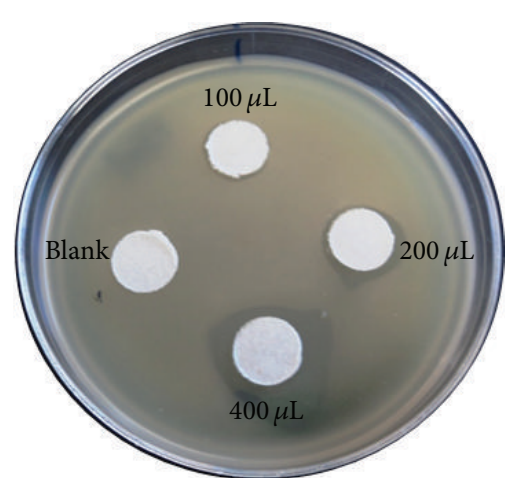

(a)

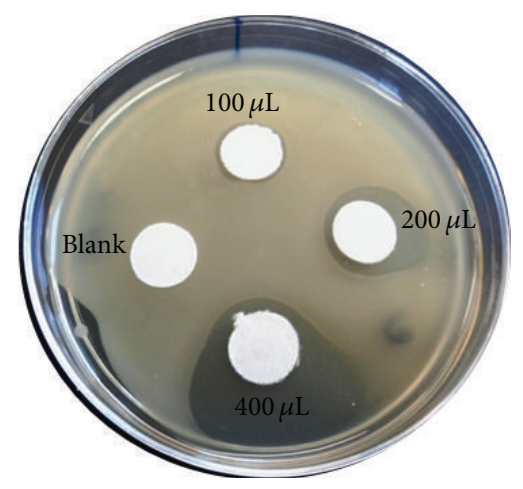

(b)

FIGURE 6: Paper disk diffusion assay of antimicrobial activity of different amounts of Ni nanoparticles solutions on E. coli: (a) $110 \mu \mathrm{M}$ and (b) $294 \mu \mathrm{M}$.

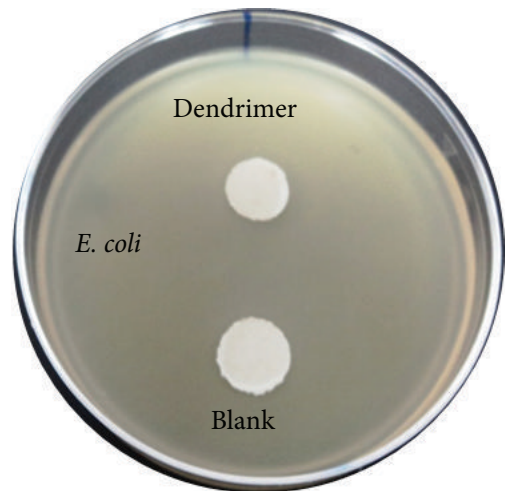

(a)

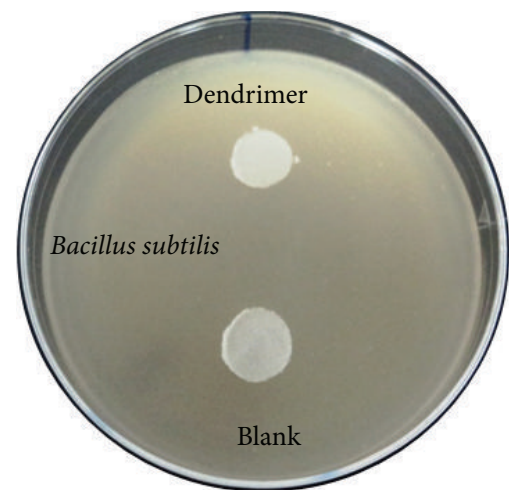

(b)

Figure 7: Paper disk diffusion assay of antimicrobial activity of $2 \mu \mathrm{M}$ of dendrimer solution against (a) E. coli and (b) Bacillus subtilis.

concentrations, which is due to penetration of the cell membrane by PAMAM dendrimers containing primary amine surface functional groups [31]. One may speculate that the dendrimer solution is adding to (or even dominating) the antimicrobial effect of the formed Ni nanoparticles. Figures 7 (a) and 7(b) show the antimicrobial activity of dendrimer solutions against cultured bacteria Escherichia coli and Bacillus subtilis, respectively. As can be observed, no visible zones of inhibition are produced when tested against low concentrations of dendrimer solutions. In short, for lower concentrations $(2 \mu \mathrm{M})$ of dendrimer solutions, no antimicrobial activity against Escherichia coli or Bacillus subtilis is observed, hence, indicating that the antimicrobial activity is solely restricted to that of the chemical activity exhibited by the dendrimer-encapsulated $\mathrm{Ni}(0)$ nanoparticles. Moreover, nickel salts showed no antimicrobial activity when tested against Escherichia coli and Bacillus subtilis (see Figures 8(a) and $8(\mathrm{~b})$ ). It has been proposed that antimicrobial agents prevent the growth of bacteria through the disrupting of the cell membrane function and inhibiting cell wall synthesis, nucleic acid synthesis, protein synthesis, and folic acid synthesis [25]. That is, Ni nanoparticles interact with the building components of the outer layer of the bacteria disrupting the cell wall and finally preventing further bacteria, and it has been suggested that antimicrobial activity should increase depending on particle size. Other reports have indicated that the larger surface-area-to-volume ratio exhibited by the smaller particles along with an increased penetrating ability will result in particles with increased effective binding on the outer membrane and cell membranes of organisms [31]. Hence, given the smaller sizes of the $\mathrm{Ni}$ particles formed here (ca. $10 \mathrm{~nm}$ in diameter), which is much smaller than a bacterium, it is conceivable to assume that the increased antimicrobial activity is a direct result of increased penetration of the microorganism cell walls.

Similar tests were completed for dendrimer-encapsulated nanoparticles against Bacillus subtilis bacteria with no activity observance from the $\mathrm{Ni}$ salt or dendrimer solutions; see Figure 9. By comparing Figures 9(a) and 9(b), we can speculate that the antibacterial activities of nickel nanoparticles are better on Gram-positive than Gram-negative bacteria. This could be attributed to the different outer structural arrangement of the bacteria walls; Gram-negative bacteria have one extra lipopolysaccharide layer when compared to Grampositive bacteria. Given the mechanism of wall penetration presented earlier, an extra wall layer could dramatically alter the antimicrobial activity of the formed nanoparticles. That is, given the thickness and uniqueness of the extra layer, 


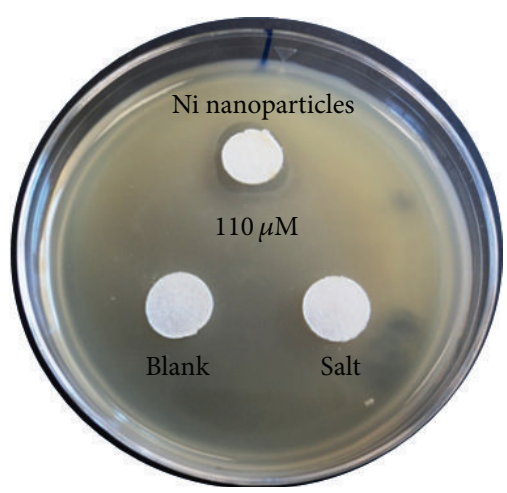

(a)

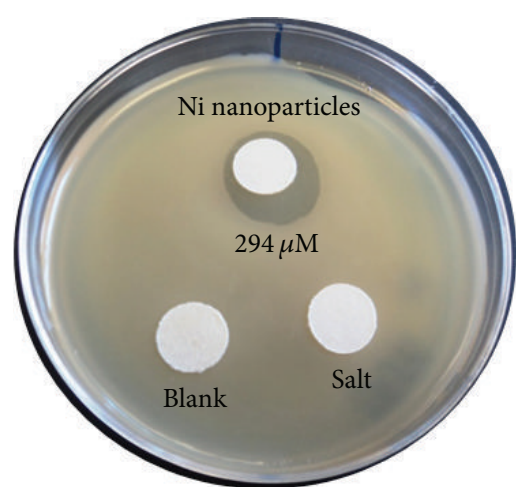

(b)

Figure 8: Paper disk diffusion assay of antimicrobial activity of dendrimer-encapsulated $\mathrm{Ni}(0)$ nanoparticles versus $\mathrm{Ni}\left(\mathrm{NO}_{3}\right)_{2} \cdot 6 \mathrm{H}_{2} \mathrm{O}$ salt solution against E. coli. $200 \mu \mathrm{L}$ of each solution was added to each disk of E. coli: (a) $110 \mu \mathrm{M}$ and (b) $294 \mu \mathrm{M}$.

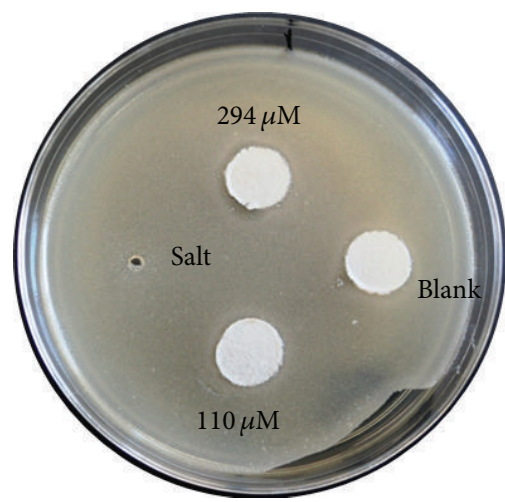

(a)

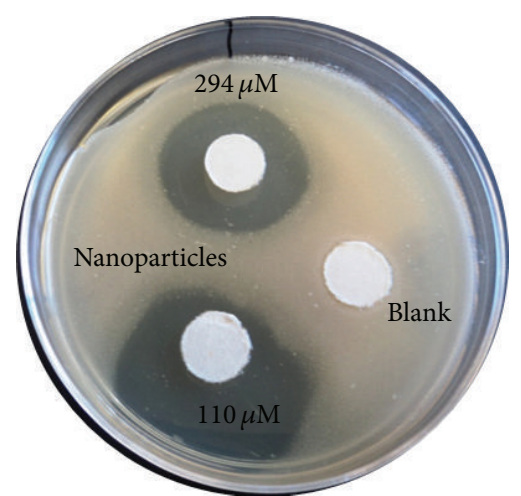

(b)

Figure 9: Paper disk diffusion assay of antimicrobial activity of dendrimer-encapsulated $\mathrm{Ni}(0)$ nanoparticles versus $\mathrm{Ni}\left(\mathrm{NO}_{3}\right)_{2} \cdot 6 \mathrm{H}_{2} \mathrm{O}$ salt solution against Bacillus Subtilis. $200 \mu \mathrm{L}$ of each solution was added to the disk of Bacillus subtilis: (a) salt and (b) Ni(0) nanoparticles.

it is plausible to speculate that the amount of time needed for nanoparticle penetration of the cell wall after attachment will be significantly increased and, hence, exhibiting less antimicrobial activity against bacteria. Moreover, based on Figure 9(b), it is apparent that the lower concentration of dendrimer-encapsulated nanoparticles is more effective at penetration of the cell walls of the bacteria. We speculate here that, in this case, reduced aggregation of the nanoparticles within the dendrimer cavity due to the lower concentration of $\mathrm{Ni}(0)$ particles allows for the observed phenomenon. In other words, it is conceivable that in the presence of higher concentration of the nanoparticles, larger particles are formed which reduces the amount of surface area available for antimicrobial activity against the bacteria.

To investigate the minimum volume of nanoparticles needed for the onset of bacteria inhibition, minimum inhibitory concentration tests were performed while monitoring growth characteristics of the E. coli bacteria (see Figure 10). Dendrimer-encapsulated $\mathrm{Ni}(0)$ nanoparticles at two concentrations, $110 \mu \mathrm{M}$ and $294 \mu \mathrm{M}$, were compared against the E. coli bacteria. From the results of the MIC test, the minimum volume of dendrimer-encapsulated $\mathrm{Ni}(0)$ particles necessary to exhibit antimicrobial activity against $E$. coli bacteria is around $20 \mu \mathrm{L}$. That is, at volumes below this critical value, no prevention of bacterial growth was observed when tested against the E. coli bacteria. As the volume of the nanoparticle solution increased, the absorbance decreased dramatically. This clearly indicates that larger amounts of bacteria have been killed. Comparatively, for the higher concentrated dendrimer-encapsulated $\mathrm{Ni}(0)$ solutions $(294 \mu \mathrm{M})$, a lower absorbance is observed when tested against the $E$. coli bacteria than the lower concentrated solution $(110 \mu \mathrm{M})$. In other words, this is a direct indication that the $\mathrm{Ni}(0)$ nanoparticles performed better at killing the bacteria at higher concentrations. These results further support the observation that regardless of the dendrimer-mediated growth and protection of the $\mathrm{Ni}(0)$ nanoparticles, antimicrobial activity is still observed against both Gram-negative and Gram-positive bacteria.

\section{Conclusions}

In this research study, we present the successful synthesis of dendrimer-mediated nickel nanoparticles with 


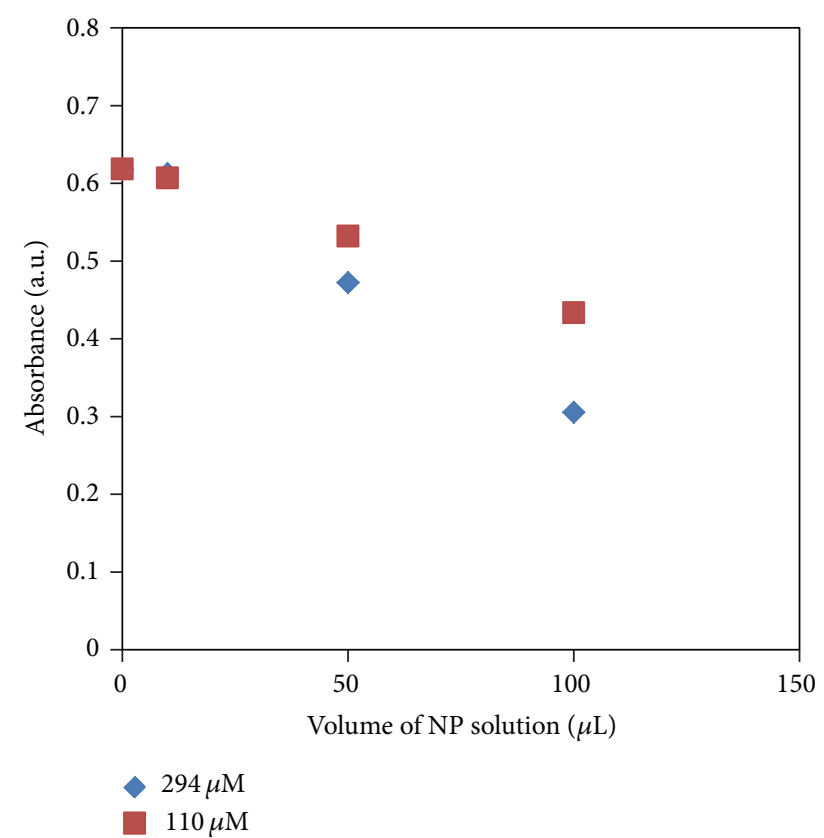

FIgURE 10: MIC test revealing the minimum volume of $\mathrm{Ni}(0)$ nanoparticles needed to exhibit antimicrobial activity against $E$. coli bacteria.

an average diameter around $10 \mathrm{~nm}$. XRD and TEM analyses revealed that the nanoparticles exhibited a single-phased, spherical in shape, fcc crystallographic structure and are monodispersed in nature. Antimicrobial tests indicated that the as-synthesized dendrimer-encapsulated nickel nanoparticles exhibited antibacterial activities against both Grampositive and Gram-negative bacteria. The activities were more pronounced in the Gram-positive bacteria as compared to the Gram-negative bacteria. In addition, paper disk diffusion assay tests revealed clear zones of inhibition for the dendrimer-encapsulated particles only indicating that the $\mathrm{Ni}(0)$ nanoparticles were effectively preventing the growth of bacteria. In addition, it was observed that the particles were more effective against bacterial growth for higher concentration of nanoparticles. MIC test revealed that the minimum volume (i.e., critical inhibiting volume) of Ni particle solution needed to initiate the onset growth prevention of bacteria was around $20 \mu \mathrm{L}$. No antimicrobial activity was observed for the low in concentration dendrimers and Ni salt. Hence, the formation of nickel nanoparticles via a dendrimer-host templating method has shown great promise as an avenue for producing antimicrobial agents. This could begin to unlock the unlimited possibilities of applications of dendrimerencapsulated metal nanoparticles to the future of research in biomedicine and the production of pharmaceuticals.

\section{Acknowledgments}

The authors would like to acknowledge the support of this work from the Center for Advance Materials Science through CREST and ESPCoR awards. Primary support of this work by the Synthesis and Characterization Center at Tuskegee University is gratefully acknowledged.

\section{References}

[1] L. Fu, Z. Liu, Y. Liu et al., "Beaded cobalt oxide nanoparticles along carbon nanotubes: towards more highly integrated electronic devices," Advanced Materials, vol. 17, no. 2, pp. 217-221, 2005.

[2] E. Talbot, R. Lardé, F. Gourbilleau, C. Dufour, and P. Pareige, "Si nanoparticles in $\mathrm{SiO}_{2}$ An atomic scale observation for optimization of optical devices," EPL, vol. 87, no. 2, Article ID 26004, 5 pages, 2009.

[3] D. M. Schaadt, B. Feng, and E. T. Yu, "Enhanced semiconductor optical absorption via surface plasmon excitation in metal nanoparticles," Applied Physics Letters, vol. 86, no. 6, Article ID 063106, 3 pages, 2005.

[4] T. W. Kim, D. U. Lee, and Y. S. Yoon, "Microstructural, electrical, and optical properties of $\mathrm{SnO}_{2}$ nanocrystalline thin films grown on InP (100) substrates for applications as gas sensor devices," Journal of Applied Physics, vol. 88, no. 6, pp. 3759-3761, 2000.

[5] J. Jang, J. Ha, and J. Cho, "Fabrication of water-dispersible polyaniline-poly(4-styrenesulfonate) nanoparticles for inkjetprinted chemical-sensor applications," Advanced Materials, vol. 19, no. 13, pp. 1772-1775, 2007.

[6] H. Zhao, H. Fu, C. Tian, Z. Ren, and G. Tian, "Fabrication of silver nanoparticles/single-walled carbon nanotubes composite for surface-enhanced Raman scattering," Journal of Colloid and Interface Science, vol. 351, no. 2, pp. 343-347, 2010.

[7] K. Kim, H. B. Lee, and K. S. Shin, "Surface-enhanced Raman scattering characteristics of nanogaps formed by a flat $\mathrm{Ag}$ substrate and spherical Pt nanoparticles," Spectrochimica Acta A, vol. 100, pp. 10-14, 2013.

[8] P. D. Burton, T. J. Boyle, and A. K. Datye, "Facile, surfactantfree synthesis of Pd nanoparticles for heterogeneous catalysts," Journal of Catalysis, vol. 280, no. 2, pp. 145-149, 2011.

[9] K. D. Bhatte, P. J. Tambade, K. P. Dhake, and B. M. Bhanage, "Silver nanoparticles as an efficient, heterogeneous and recyclable catalyst for synthesis of $\beta$-enaminones," Catalysis Communications, vol. 11, no. 15, pp. 1233-1237, 2010.

[10] B. J. Auten, B. P. Hahn, G. Vijayaraghavan, K. J. Stevenson, and B. D. Chandler, "Preparation and characterization of $3 \mathrm{~nm}$ magnetic NiAu nanoparticles," Journal of Physical Chemistry C, vol. 112, no. 14, pp. 5365-5372, 2008.

[11] Q. A. Pankhurst, N. K. T. Thanh, S. K. Jones, and J. Dobson, "Progress in applications of magnetic nanoparticles in biomedicine," Journal of Physics D, vol. 42, no. 22, Article ID 224001, 2009.

[12] J. Tian, K. K. Y. Wong, C. Ho et al., “Topical delivery of silver nanoparticles promotes wound healing," ChemMedChem, vol. 2, no. 1, pp. 129-136, 2007.

[13] Y. H. Kim, D. K. Lee, H. G. Cha, C. W. Kim, and Y. S. Kang, "Synthesis and characterization of antibacterial $\mathrm{Ag}-\mathrm{SiO}_{2}$ nanocomposite," Journal of Physical Chemistry C, vol. 111, no. 9, pp. 3629-3635, 2007.

[14] T. Theivasanthi and M. Alagar, "Studies of copper nanoparticles effects on micro organisms," Annals of Biological Research, vol. 2, no. 3, pp. 368-373, 2011.

[15] H. Cohen, R. J. Levy, J. Gao et al., "Sustained delivery and expression of DNA encapsulated in polymeric nanoparticles," Gene Therapy, vol. 7, no. 22, pp. 1896-1905, 2000. 
[16] G. Reiss and A. Hütten, "Magnetic nanoparticles: applications beyond data storage," Nature Materials, vol. 4, no. 10, pp. 725726, 2005.

[17] J. R. Morones, J. L. Elechiguerra, A. Camacho et al., "The bactericidal effect of silver nanoparticles," Nanotechnology, vol. 16, no. 10, pp. 2346-2353, 2005.

[18] S. Ravikumar, R. Gokulakrishnan, and P. Boomi, "In vitro antibacterial activity of the metal oxide nanoparticles against urinary tract infectious bacterial pathogens," Asian Pacific Journal of Tropical Disease, vol. 2, no. 2, pp. 85-89, 2012.

[19] J. P. Ruparelia, A. K. Chatterjee, S. P. Duttagupta, and S. Mukherji, "Strain specificity in antimicrobial activity of silver and copper nanoparticles," Acta Biomaterialia, vol. 4, no. 3, pp. 707-716, 2008.

[20] G. Ren, D. Hu, E. W. C. Cheng, M. A. Vargas-Reus, P. Reip, and R. P. Allaker, "Characterisation of copper oxide nanoparticles for antimicrobial applications," International Journal of Antimicrobial Agents, vol. 33, no. 6, pp. 587-590, 2009.

[21] Y. Zhang, H. Peng, W. Huang, Y. Zhou, and D. Yan, "Facile preparation and characterization of highly antimicrobial colloid Ag or Au nanoparticles," Journal of Colloid and Interface Science, vol. 325, no. 2, pp. 371-376, 2008.

[22] J. F. G. A. Jansen, E. W. Meijer, and E. M. M. de Brabandervan den Berg, "The dendritic box: shape-selective liberation of encapsulated guests," Journal of the American Chemical Society, vol. 117, no. 15, pp. 4417-4418, 1995.

[23] Y. Hou, H. Kondoh, T. Ohta, and S. Gao, "Size-controlled synthesis of nickel nanoparticles," Applied Surface Science, vol. 241, no. 1-2, pp. 218-222, 2005.

[24] M. R. Knecht, J. C. Garcia-Martinez, and R. M. Crooks, "Synthesis, characterization, and magnetic properties of dendrimerencapsulated nickel nanoparticles containing < 150 atoms," Chemistry of Materials, vol. 18, pp. 5039-5044, 2006.

[25] C. M. Mann and J. L. Markham, "A new method for determining the minimum inhibitory concentration of essential oils," Journal of Applied Microbiology, vol. 84, no. 4, pp. 538-544, 1998.

[26] F. Zeng and S. C. Zimmerman, "Dendrimers in supramolecular chemistry: from molecular recognition to self-assembly," Chemical Reviews, vol. 97, no. 5, pp. 1681-1712, 1997.

[27] K. J. Carroll, J. U. Reveles, M. D. Shultz, S. N. Khanna, and E. E. Carpenter, "Preparation of elemental $\mathrm{Cu}$ and $\mathrm{Ni}$ nanoparticles by the polyol method: an experimental and theoretical approach," Journal of Physical Chemistry C, vol. 115, no. 6, pp. 2656-2664, 2011.

[28] W. Wang, Y. Itoh, I. W. Lenggoro, and K. Okuyama, "Nickel and nickel oxide nanoparticles prepared from nickel nitrate hexahydrate by a low pressure spray pyrolysis," Materials Science and Engineering B, vol. 111, no. 1, pp. 69-76, 2004.

[29] K. Harish, R. Renu, and S. R. Kumar, "Synthesis of nickel hydroxide nanoparticles by reverse micelle method and its antimicrobial activity," Research Journal of Chemical Sciences, vol. 1, no. 9, pp. 42-48, 2011.

[30] R. A. Varin and C. Chiu, "Structural stability of sodium borohydride $\left(\mathrm{NaBH}_{4}\right)$ during controlled mechanical milling," Journal of Alloys and Compounds, vol. 397, no. 1-2, pp. 276-281, 2005.

[31] S. Ghosh, D. Ghosh, P. K. Bag, S. C. Bhattacharya, and A. Saha, "Aqueous synthesis of ZnTe/dendrimer nanocomposites and their antimicrobial activity: implications in therapeutics," Nanoscale, vol. 3, no. 3, pp. 1139-1148, 2011. 

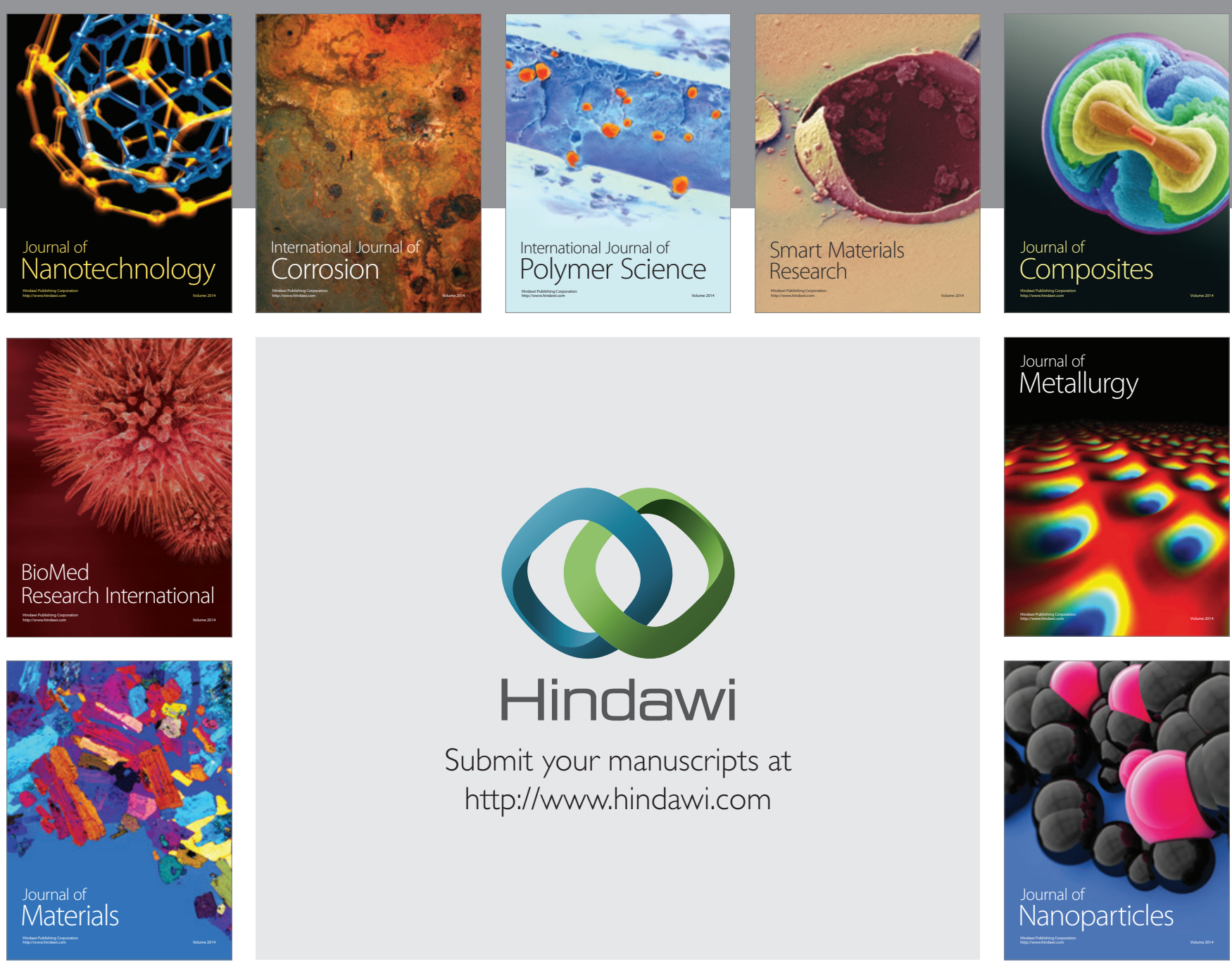

Submit your manuscripts at http://www.hindawi.com
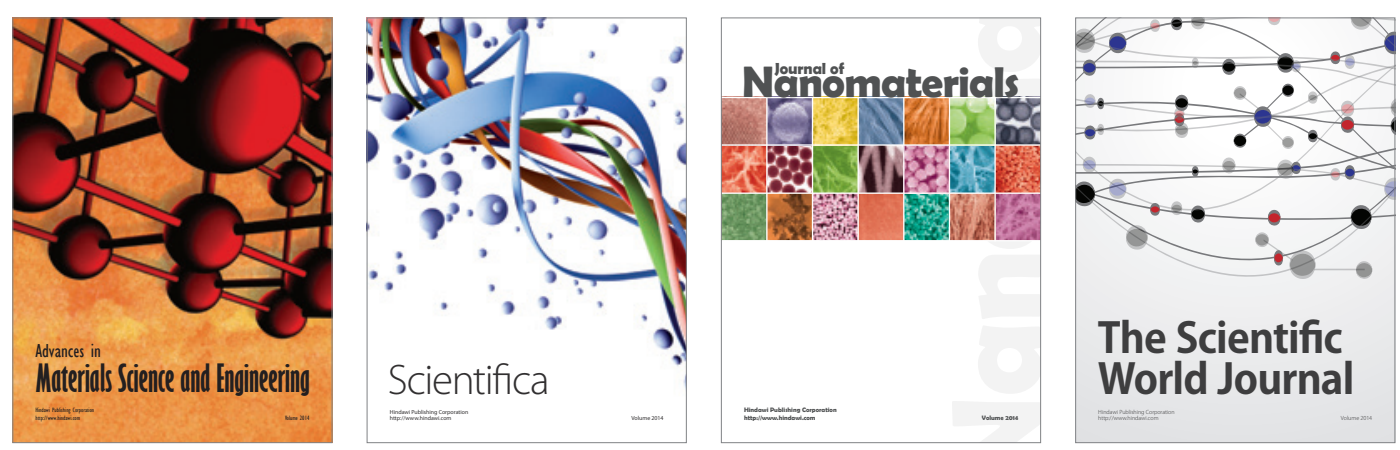

\section{The Scientific World Journal}
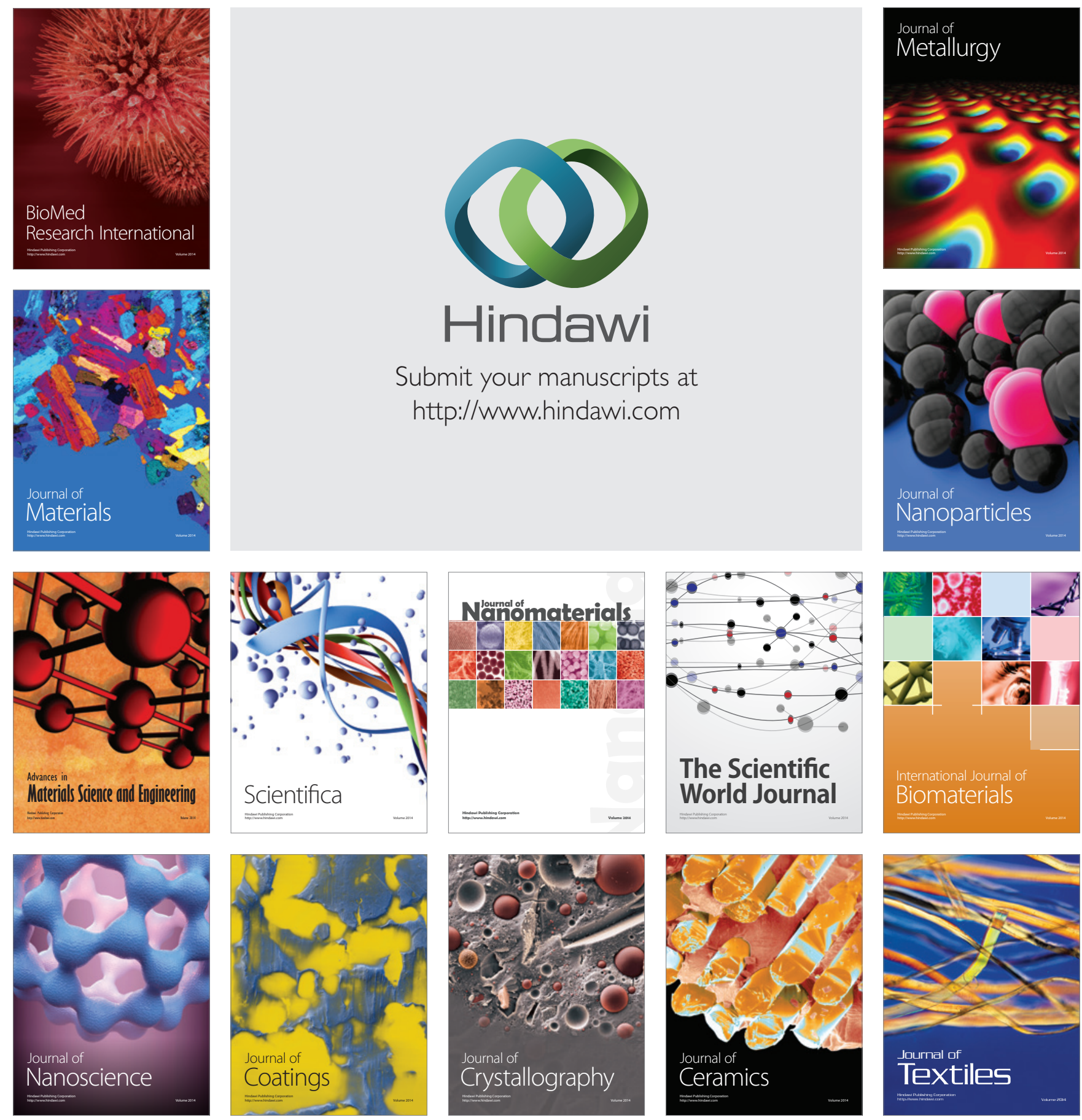